\title{
Iron status and erythropoiesis response to darbepoetin alfa in dogs with chronic kidney disease
}

\author{
Chayanont BHAMARASUTA ${ }^{1)}$, Kanyavee PREMRATANACHAI ${ }^{1}$, \\ Nitchanan MONGKOLPINYOPAT ${ }^{1)}$, Pamila YOTHAPAND ${ }^{1)}$, \\ Thitapa VEJPATTARASIRI ${ }^{1)}$, Thasinas DISSAYABUTRA ${ }^{2)}$, Monkon TRISIRIROJ ${ }^{3)}$, \\ Saikaew SUTAYATRAM ${ }^{1)}$ and Chollada BURANAKARL ${ }^{1) *}$ \\ ${ }^{1)}$ Department of Physiology, Faculty of Veterinary Science, Chulalongkorn University, Henri Dunant Rd., \\ Pathumwan, Bangkok, 10330, Thailand \\ ${ }^{2)}$ STAR unit of Renal Biochemistry and Stone Disease, Department of Biochemistry, Faculty of Medicine, \\ Chulalongkorn University, Henri Dunant Rd., Pathumwan, Bangkok, 10330, Thailand \\ 3) The Small Animal Teaching Hospital, Faculty of Veterinary Science, Chulalongkorn University, Henri Dunant \\ Rd., Pathumwan, Bangkok, 10330, Thailand
}

J. Vet. Med. Sci.

83(4): 601-608, 2021

doi: 10.1292/jvms.20-0574

Received: 27 September 2020 Accepted: 28 January 2021 Advanced Epub:

9 February 2021

\begin{abstract}
Iron metabolism, hepcidin and some blood profiles were investigated in 13 healthy and 31 chronic kidney disease (CKD) dogs. The study consisted of 2 experiments, experiment I included healthy dogs (CONT) and CKD dogs (stage 2, 3 and 4), while experiment II consisted of anemic CKD dogs subjected to 28-day darbepoetin alfa treatment. The response to darbepoetin alfa could divide anemic CKD dogs into responder (RP) and non-responder (NRP) subgroups. The results from experiment I showed that packed cell volume (PCV) and plasma albumin concentration were significantly lower in CKD dogs of all stages while the total iron binding capacity (TIBC) was lower in only CKD stage 3 and 4 compared with dogs in CONT group. The PCV was related to both TIBC and albumin when considering among all dogs or only in CKD dogs. The hepcidin concentration in CKD dogs with anemia was lower than those without anemia $(P<0.05)$. In experiment II before darbepoetin alfa treatment, RP subgroup had significantly higher iron and TIBC compared with NRP subgroup $(P<0.05)$, the iron concentration was decreased only in RP subgroup after darbepoetin alfa treatment $(P<0.05)$. The percent increase in PCV was correlated with initial TIBC $(P<0.01)$. Plasma hepcidin concentration was not different between CONT and CKD groups and between RP and NRP subgroups both before and after darbepoetin alfa treatment. It is concluded that TIBC and plasma iron concentration play role on anemia and erythropoietic response to darbepoetin alfa treatment in CKD dogs.

KEY WORDS: chronic kidney disease, darbepoetin alfa, dog, hepcidin, iron
\end{abstract}

Chronic kidney disease (CKD) is a metabolic disorder with a progressive deterioration of renal function that was commonly found in geriatric dogs and cats. The prevalence rate in dogs was approximately $0.37 \%$ in dogs [30] and 0.4 to $50 \%$ in cats [24, 31]. Non-regenerative anemia usually develops as a feature of CKD when the disease progresses to the end stage. Approximately $70 \%$ of dogs with CKD will develop anemia as their renal disease progresses while the predominant cause is decreased production of erythropoietin (EPO) [22]. Additionally, the response to EPO could be subsided due to lack of iron bioavailability. Measurements of iron, total iron binding capacity (TIBC) and ferritin are available in clinical practice.

The relationship between indices of iron status and changes in acute phase proteins (APPs) during inflammation was reviewed in humans [29]. Hepcidin which is produced by the hepatocyte, is one of the APPs described as a major regulator of iron homeostasis and linkage between anemia and inflammation. Hepcidin suppresses iron release, bioavailability and intestinal iron absorption that may contribute to anemia of CKD [11]. The hepcidin level was used as biomarker for iron status and EPO resistance in CKD patient [38]. Besides human patient, hepcidin was also higher, where as TIBC and total iron concentration were lower in CKD cats [18]. One study showed that mechanism of hepcidin suppression by EPO involves erythroferrone synthesis rather than binding to EPO receptor in the liver [10]. Recently, the EPO has been replaced by EPO analogue, darbepoetin alfa, in veterinary practice since it has longer half-life which allowing less frequency dosing and causing less anti-erythropoietin antibodies in dogs as reviewed earlier [7]. 
The role of iron and hepcidin on anemia in CKD as well as erythropoiesis response after EPO analogue administration has not yet been evaluated in dogs. The objectives of this study were to investigate the differences in iron, TIBC and hepcidin levels between 1) normal healthy and CKD dogs and 2) anemic CKD dogs before and after darbepoetin alfa administration.

\section{MATERIALS AND METHODS}

The study was performed in client-owned dogs that presented to The Small Animal Teaching Hospital, Faculty of Veterinary Science, Chulalongkorn University between August 2018 and October 2019. The protocol was approved by the Institutional Animal Care and Use Committee (protocol No. 1831082), and additional consent forms were obtained from all owners. Iron parameters and hepcidin were evaluated in CKD dogs compared with healthy dogs (experiment I) and in anemic CKD dogs before and after 28 days of darbepoetin alfa treatment (experiment II).

\section{Animals and criteria}

Experiment I: Dogs were divided into 2 groups; healthy control; (CONT) and CKD groups. All dogs were classified and confirmed health status by veterinarian based on medical history, physical examination, radiographic imaging or ultrasonography and laboratory evaluation. The CONT group are healthy dogs of both sexes of any breeds with clinically healthy and had both plasma creatinine and symmetric dimethylarginine (SDMA) less than $1.4 \mathrm{mg} / \mathrm{dl}$ and $18 \mu \mathrm{g} / \mathrm{dl}$, respectively. Dogs in CKD group were dogs that had plasma creatinine and SDMA concentrations higher than $1.4 \mathrm{mg} / \mathrm{dl}$ and $18 \mu \mathrm{g} / \mathrm{dl}$, respectively. The CKD group was also sub-staged according to International Renal Interest Society, 2019 [17] into CKD stage 2 (CKD-2), 3 (CKD-3) and 4 (CKD-4) based on plasma creatinine concentrations as being 1.4-2.8, 2.9-5.0 and >5.0 mg/dl, respectively. The SDMA, although was measured in some dogs in CKD group, was not used to categorize stage of CKD. Dogs that receiving treatments with erythropoietin (EPO), darbepoetin alfa or blood transfusion for 1 month prior to the study were excluded.

Experiment II: Study was conducted in the CKD dogs that had packed cell volume (PCV) less than $28 \%$ and were considered by clinicians that required darbepoetin alfa treatment. These patients were subclassified into 2 subgroups, responder (RP) and non-responder (NRP) subgroups. The dogs in RP subgroup were defined as dogs in which PCV was increased more than $10 \%$ of absolute value from baseline or PCV value was higher than $30 \%$ as categorized earlier [7] when measured at 28 days after weekly administration of darbepoetin alfa, whereas dogs in NRP subgroup did not achieve these conditions.

\section{Experimental procedure}

All dogs in the experiment I were subjected to physical examination and blood collection on the day of the study. Blood samples were collected from cephalic or saphenous venipuncture. The $0.5 \mathrm{ml}$ of blood was put in tubes containing ethylenediamine tetraacetic acid (EDTA) for determination of PCV and while blood cell count (WBC), while another 0.5 ml was put in heparinized tube for measurements of blood chemistries (blood urea nitrogen; BUN, creatinine; Cr, alanine aminotransferase; ALT, total protein; TP and albumin). Additional $2 \mathrm{ml}$ of blood were collected into plain tubes, allowed to clot, and then centrifuged at $4{ }^{\circ} \mathrm{C}$, $1,000 \mathrm{~g}$ for $15 \mathrm{~min}$ to separate serum. Approximate by $500 \mu \mathrm{l}$ of serum was kept at $2^{\circ} \mathrm{C}$ for measurement of iron concentration and total iron binding capacity while the rest was frozen at $-80^{\circ} \mathrm{C}$ until analysis for SDMA and hepcidin concentrations.

For the experiment II, CKD dogs that had anemia (PCV $<28 \%)$ were then subjected to administration of darbepoetin alfa $\left(\mathrm{NESP}^{\circledR} 30 \mu \mathrm{g} / 0.5 \mathrm{ml}\right.$, Terumo Co., Kofu Factory, Nakakoma, Japan) at a dose of $1 \mu \mathrm{g} / \mathrm{kg}$, subcutaneously, approximately once a week for 4 weeks. Blood was recollected and iron parameters and hepcidin were measured at day 28 after darbepoetin alfa treatment.

\section{Analytical procedure}

The automated analyzer was used for measurements of CBC (Mindray BC-5000VET, Shenzhen Mindray Bio-Medical Electronics Co., Ltd., Shenzhen, China) and serum chemistry profiles (BUN, Cr, ALT, TP and albumin) (ILAB 650 Chemistry Analyzer, Diamond diagnostics, Holliston, MA, USA). The concentration of serum SDMA was measured by commercial analyzer (Vcheck V200, Bionote Co., Ltd., Gyeonggi-do, South Korea). The information from manufacturer showed the close relationship between concentration of SDMA obtained from this kit and from gold standard "I" laboratory $\left(\mathrm{R}^{2}=0.9908\right)$. This method had the lowest detecting value of $10 \mu \mathrm{g} / \mathrm{dl}$ and highest detecting value of $100 \mu \mathrm{g} / \mathrm{dl}$. For iron parameters, serum iron concentration and unsaturated iron binding capacity (UIBC) were analyzed by the standard colorimetric Ferrozine method (Cobas c501, Roche Diagnostics, Indianapolis, IN, USA). The TIBC was calculated as TIBC=UIBC + serum iron concentration. Serum hepcidin levels were measured by Sandwich quantitative ELISA technique using canine hepcidin (HEPC) ELISA kit (Catalogue \# MBS010437; MyBiosource Inc., San Diego, CA, USA). The percent saturation (\%Sat) was calculated as the ratio of serum iron concentration to TIBC.

\section{Statistical analysis}

Statistical analyses were performed with commercial software (Sigma Stat ${ }^{\circledR}$ version 12.0). All parameters are presented as mean \pm standard error of the mean (SEM). The One-way Analysis of Variance (ANOVA) or ANOVA on rank were used to compared data between each stage of CKD and CONT group. The Dunnett and Dunn tests were used for pairwise comparison. Comparisons of iron parameters in CKD dogs between either anemia and non-anemia groups or between dogs with iron and without iron supplementation were performed using unpaired $t$-test or Mann-Whitney $U$ test. Data between RP and NRP subgroups at the same period were compared by unpaired $t$-test or Mann-Whitney $U$ test whereas data obtained before and after 28 days of darbepoetin 
alfa treatment in the same group were compared using Paired $t$-test or Wilcoxon signed-rank test. Pearson correlation was used to determine relationships between variables. $P$-value less than 0.05 was considered statistically significant difference.

\section{RESULTS}

\section{Experiment I}

A total of 44 dogs were included in this study. Thirteen of dogs were in CONT group, while 31 were in CKD group which composed of 9, 14 and 8 dogs in CKD-2, CKD-3 and CKD-4, respectively. The age, weight, breed, sex and coexisting diseases of each group were shown in Table 1 . Only CKD-2 had higher age than CONT dogs $(P<0.01)$. The average weight was not different among groups. Eighteen from $31 \mathrm{CKD}$ dogs received iron as supplementation at an average dose of 65 (range 20-98) mg/dog/day for an average duration of 78 (range 1-391) days. The incidence of CKD can be detected in both male and female regardless of sterilization. The coexisting diseases found in CKD including blood parasite, pancreatitis and urinary tract infection.

All of CKD dogs consumed renal diets. None of dogs in CONT and CKD-2 groups had clinical signs of anorexia and lethargy while they were appeared in CKD-3 (3/14) and CKD-4 (4/8). The urinalysis results could be obtained in some CKD dogs. The average urine specific gravity in some $\mathrm{CKD} \operatorname{dogs}(\mathrm{n}=22)$ were $1.015 \pm 0.001$ while proteinuria of $+3,+2,+1$ were found in 3,11 and 6 dogs, respectively. Two dogs did not present with proteinuria.

Blood parameters and chemistries: The SDMA in all dogs of CONT group were lower than $18 \mu \mathrm{g} / \mathrm{dl}(7 \mathrm{dogs}$ had SDMA $<10$ $\mu \mathrm{g} / \mathrm{dl}$ while $6 \mathrm{dogs}$ had SDMA between 11-12 $\mu \mathrm{g} / \mathrm{dl}$ ). The BUN concentrations of CKD dogs in all stage groups were significantly higher than CONT group $(P<0.05)$ while the creatinine concentrations were higher in CKD-3 and CKD-4 groups compared with CONT group $(P<0.05)$ (Table 2). The PCV of dogs in all stages of CKD was significantly lower than CONT group $(P<0.001)$ while WBC showed no difference. Among CKD dogs, number of dogs that showed anemia (PCV $<28 \%$ ) were $2 / 9,11 / 14$ and $3 / 8$ in CKD-2, CKD-3 and CKD-4 groups, respectively while none were found in CONT group. The albumin in all CKD groups was significantly lower than CONT group $(P<0.05)$. The TP and ALP were not different between CKD groups and CONT group.

Iron parameters and hepcidin: Plasma iron concentration was not different between CKD groups and CONT group (Table 2). The TIBC was significantly lower in CKD-3 and CKD-4 groups compared with CONT group $(P<0.05)$. The degree of reduction in

Table 1. Baseline characteristics of dogs in each group

\begin{tabular}{|c|c|c|c|c|}
\hline Variables & $\begin{array}{l}\text { CONT } \\
(\mathrm{n}=13)\end{array}$ & $\begin{array}{c}\mathrm{CKD}-2 \\
(\mathrm{n}=9)\end{array}$ & $\begin{array}{l}\text { CKD-3 } \\
(\mathrm{n}=14)\end{array}$ & $\begin{array}{c}\text { CKD-4 } \\
(\mathrm{n}=8)\end{array}$ \\
\hline Age (years) & $7.7 \pm 1.3$ & $14.0 \pm 0.4^{* *}$ & $9.4 \pm 1.2$ & $10.5 \pm 1.6$ \\
\hline Weight (kg) & $11.6 \pm 2.7$ & $11.1 \pm 2.6$ & $14.6 \pm 2.7$ & $17.3 \pm 3.2$ \\
\hline \multicolumn{5}{|l|}{ Breeds } \\
\hline Mixed & 2 & 2 & 5 & 5 \\
\hline Golden Retriever & & 1 & 2 & 1 \\
\hline Shih Tzu & 1 & 1 & 1 & \\
\hline Siberian Husky & 2 & & & \\
\hline Beagle & 1 & & 1 & \\
\hline Chihuahua & 2 & 1 & & \\
\hline Poodle & 2 & & & \\
\hline Pomeranian & 1 & & 1 & \\
\hline Schnauzer & 1 & & 1 & \\
\hline Labrador Retriever & & 1 & & \\
\hline Miniature Pinoscher & & & 1 & 1 \\
\hline Thai Bangkaew & & & & 1 \\
\hline Fox Terrier & & 1 & & \\
\hline Pug & & 1 & & \\
\hline Pitbull & & & 1 & \\
\hline Border Collies & 1 & & & \\
\hline French Bulldog & & & 1 & \\
\hline West Highland White Terrier & & 1 & & \\
\hline \multicolumn{5}{|l|}{ Gender } \\
\hline $\mathrm{M} / \mathrm{Mc} / \mathrm{F} / \mathrm{Fs}$ & $8 / 1 / 4 /-$ & $4 / 1 / 1 / 3$ & $6 / 3 / 1 / 4$ & $2 / 3 / 1 / 2$ \\
\hline \multirow[t]{3}{*}{ Co-existing diseases } & - & $\begin{array}{l}\text { 1-E. canis } \\
\text { +A. Spp. }\end{array}$ & 5-E. canis & 1-A. Spp. \\
\hline & & 2-Cystitis & 1-Renal calculi & 1-Pancreatitis \\
\hline & & 1-Pancreatitis & $\begin{array}{l}\text { 1-Pyelonephritis } \\
\text { 1-Lymphoma }\end{array}$ & 1-Cystic calculi \\
\hline
\end{tabular}

Data are presented as mean \pm standard error of mean. ${ }^{* *} P<0.01$ compared with CONT group using one way ANOVA. CONT: control; CKD: chronic kidney disease; M: intact male; Mc: castrated male; F: intact female; Fs: spayed female; E. Canis: Ehrlichia canis; A. spp.: Anaplasma species. Number in front indicates the number of dog. 
Table 2. Blood parameters, blood chemistries and iron parameters of dogs in control and chronic kidney disease groups

\begin{tabular}{lcccc}
\hline \multicolumn{1}{c}{ Parameters } & $\begin{array}{c}\text { CONT } \\
(\mathrm{n}=13)\end{array}$ & $\begin{array}{c}\text { CKD-2 } \\
(\mathrm{n}=9)\end{array}$ & $\begin{array}{c}\text { CKD-3 } \\
(\mathrm{n}=14)\end{array}$ & $\begin{array}{c}\text { CKD-4 } \\
(\mathrm{n}=8)\end{array}$ \\
\hline BUN $(\mathrm{mg} / \mathrm{dl})$ & $17.62 \pm 1.47$ & $57.72 \pm 8.28^{*}$ & $83.17 \pm 8.15^{*}$ & $127.59 \pm 26.91^{*}$ \\
Creatinine $(\mathrm{mg} / \mathrm{dl})$ & $0.81 \pm 0.06$ & $2.02 \pm 0.11$ & $4.01 \pm 0.17^{*}$ & $10.09 \pm 2.62^{*}$ \\
PCV $(\%)$ & $43.43 \pm 1.39$ & $26.53 \pm 3.02^{* * *}$ & $24.96 \pm 1.88^{* * *}$ & $26.34 \pm 3.06^{* * *}$ \\
WBC $\left(10^{3} \mathrm{cells} / \mu 1\right)$ & $9.41 \pm 0.69$ & $16.57 \pm 3.54$ & $13.61 \pm 2.52$ & $15.46 \pm 3.62$ \\
Albumin $(\mathrm{g} / \mathrm{dl})$ & $3.41 \pm 0.09$ & $2.33 \pm 0.15^{*}$ & $2.15 \pm 0.10^{*}$ & $2.16 \pm 0.15^{*}$ \\
TP $(\mathrm{g} / \mathrm{dl})$ & $6.65 \pm 0.15$ & $6.63 \pm 0.22$ & $6.51 \pm 0.23$ & $6.43 \pm 0.43$ \\
ALT $(\mathrm{Units})$ & $73.3 \pm 20.2$ & $80.2 \pm 27.1$ & $53.6 \pm 10.3$ & $55.1 \pm 14.1$ \\
Iron $(\mu \mathrm{g} / \mathrm{dl})$ & $136.5 \pm 12.0$ & $108.4 \pm 16.7$ & $92.7 \pm 9.3$ & $134.8 \pm 22.4$ \\
TIBC $(\mu \mathrm{g} / \mathrm{dl})$ & $368.0 \pm 23.0$ & $303.0 \pm 36.1$ & $277.1 \pm 34.3^{*}$ & $254.6 \pm 26.6^{*}$ \\
\%Sat & $38.85 \pm 3.82$ & $37.71 \pm 5.04$ & $36.74 \pm 4.16$ & $54.44 \pm 10.02$ \\
Hepcidin $(\mathrm{ng} / \mathrm{ml})$ & $81.56 \pm 29.30$ & $13.03 \pm 6.42$ & $54.04 \pm 25.11$ & $34.08 \pm 13.16$ \\
\hline
\end{tabular}

Data are presented as mean \pm standard error of mean. $* P<0.05 ; * * * P<0.001$ compared with CONT group using one-way ANOVA. CONT: control; CKD: chronic kidney disease; BUN: Blood urea nitrogen; PCV: Packed cell volume; TP: Total protein; ALT: Alanine aminotransaminase; TIBC: Total iron binding capacity; \%Sat: The percent saturation of TIBC binding to iron.

TIBC was consistent to stage of CKD. The \%Sat and hepcidin concentrations were not different between CONT and CKD groups.

When considering the iron parameter in CKD dogs with and without anemia, the anemic dogs had significantly lower TIBC and hepcidin concentration compared with non-anemic dogs $(P<0.05)$ (Table 3). Giving iron supplementation in CKD dogs had no effects on iron parameters (Table 3).

Relationships between parameters: The relationships among some parameters in all dogs were shown in Table 4. The PCV correlated positively with plasma albumin, TIBC and iron concentrations. Plasma albumin concentration also had relationships with iron and TIBC.

\section{Experiment II}

Before and after treatment of darbepoetin alfa for 28 days: A total of 10 CKD dogs with PCV less than $28 \%$ in experiment I were enrolled, and data were shown in Table 5. The initial values of iron and TIBC before darbepoetin alfa treatment in RP subgroup were significantly higher than NRP subgroup $(P<0.05)$. Iron was significantly reduced in RP subgroup after darbepoetin alfa treatment $(P<0.05)$. The \%Sat and plasma hepcidin concentration were not different in both subgroups either before or after darbepoetin alfa treatment.

The percentage increase in PCV had significant positive relationship only with initial TIBC before darbepoetin alfa administration $(r=0.785, P<0.007, \mathrm{n}=10)$ (Fig. 1). No relationship was found with other parameters.

The results of proteinuria from urinalysis were obtained from 4 and 5 dogs in RP and NRP groups, respectively. The number of dogs that had proteinuria from low to high $(0 /+1 /+2 /+3)$ were $2 / 1 / 2 / 0$ dogs in RP group and 0/0/4/1 in NRP group.

\section{DISCUSSION}

\section{Experiment I}

In the present study, CKD dogs in this study were slightly older than healthy dogs in CONT group. The breeds of dogs in all groups were variable which may depend on the demographic distribution of breed in different countries. Dogs in CONT group had plasma creatinine and SDMA values lower than $1.4 \mathrm{mg} / \mathrm{dl}$ and $18 \mu \mathrm{g} / \mathrm{dl}$, respectively, as categorized by IRIS group [17]. The severity of renal functional impairment can be evaluated using plasma concentrations of BUN, Cr and SDMA. The SDMA was a biomarker for early detection of renal dysfunction [5, 26]. It was more sensitive for kidney functional loss than plasma creatinine $[12,26]$ with less influences by extra-renal factors $[13,32]$. SDMA has been introduced in conjunction with creatinine for staging of CKD by IRIS in 2016 [16] and the number was modified in 2019 [17]. The cut-off value for renal impairment of SDMA was changed from $14 \mu \mathrm{g} / \mathrm{dl}$ to $18 \mu \mathrm{g} / \mathrm{dl}$ for higher specificity [25].

The PCV values of dogs in all CKD groups were significantly lower than those in CONT group. One dog in CKD group had GI bleeding while another one had hematuria. These two dogs may encounter the low PCV due to blood loss. However, a common cause of anemia in CKD is the lack of EPO synthesized from the kidney. King and coworkers (1992) [22] found that dogs that had chronic kidney disease could produce EPO but the concentration is too low even when dogs had severe anemia. The EPO is synthesized from peritubular cells of the renal cortex and outer medulla. The major target of EPO is the erythroid progenitor cell located in the bone marrow. The regulation of EPO production related to hypoxia has been reviewed [19]. Moreover, the decreased EPO production may be found in cases of infection or inflammation [39]. Although the WBC counts in all CKD groups in the present study was slightly higher than CONT group, the difference was not reached statistical significance.

Iron status is commonly evaluated by assessment of serum-based biochemical indicators including serum iron concentration, ferritin concentration and transferrin [1]. Serum iron concentration is represented only $<0.1 \%$ of total body iron and mostly bound to iron transport protein, transferrin. Ferritin, an iron storage protein, is a better indicator of total body iron contents and increased 
Table 3. The packed cell volume and iron status in chronic kidney disease dogs with and without anemia and in chronic kidney disease dogs with and without supplementation of iron

\begin{tabular}{lcccc}
\hline \multicolumn{1}{c}{ Parameters } & $\begin{array}{c}\text { Non-anemia } \\
(\mathrm{n}=8)\end{array}$ & $\begin{array}{c}\text { Anemia } \\
(\mathrm{n}=23)\end{array}$ & $\begin{array}{c}\text { With iron } \\
(\mathrm{n}=18)\end{array}$ & $\begin{array}{c}\text { Without iron } \\
(\mathrm{n}=13)\end{array}$ \\
\hline PCV $(\%)$ & $36.5 \pm 2.1$ & $22.1 \pm 0.9^{* * *}$ & $25.8 \pm 1.8$ & $25.7 \pm 2.3$ \\
Iron $(\mu \mathrm{g} / \mathrm{dl})$ & $121.6 \pm 18.2$ & $103.4 \pm 10.2$ & $102.6 \pm 9.4$ & $115.8 \pm 16.8$ \\
TIBC $(\mu \mathrm{g} / \mathrm{dl})$ & $371.0 \pm 52.6$ & $246.8 \pm 14.8^{*}$ & $303.7 \pm 26.7$ & $244.5 \pm 26.8$ \\
Hepcidin $(\mathrm{ng} / \mathrm{ml})$ & $47.3 \pm 11.7$ & $33.4 \pm 15.9^{*}$ & $48.6 \pm 19.5$ & $20.9 \pm 9.4$ \\
\%Sat & $37.7 \pm 8.8$ & $42.9 \pm 3.9$ & $35.0 \pm 2.8$ & $50.7 \pm 7.2$ \\
\hline
\end{tabular}

Data are presented as mean \pm standard error of mean. $* P<0.05, * * * P<0.001$ compared with non-anemia group using unpaired $t$-test or Mann-Whitney $U$ test. PCV: Packed cell volume; TIBC: Total iron binding capacity; \%Sat: The percent saturation of TIBC binding to iron.

Table 4. The correlation coefficient; $r$ (upper) and $P$-values (lower) between selected parameters

\begin{tabular}{lcccc}
\hline Parameters & Iron & TIBC & Hepcidin & Albumin \\
\hline PCV & 0.349 & 0.452 & 0.247 & 0.744 \\
& 0.020 & 0.002 & 0.106 & $<0.001$ \\
Iron & & 0.288 & 0.243 & 0.410 \\
& & 0.058 & 0.112 & 0.006 \\
TIBC & & 0.080 & 0.342 \\
& & & 0.604 & 0.023 \\
Hepcidin & & & & 0.293 \\
& & & & 0.054 \\
\hline
\end{tabular}

PCV: packed cell volume; TIBC: total iron binding capacity.

Table 5. Selected hematologic and serum values in chronic kidney disease dogs receiving darbepoetin alfa before and after 28 days of treatment, separated as responder (RP) $(\mathrm{n}=4)$ and non-responder (NRP) ( $\mathrm{n}=6)$ subgroups

\begin{tabular}{lccccc}
\hline \multirow{2}{*}{\multicolumn{1}{c}{ Parameters }} & \multicolumn{2}{c}{ RP } & \multicolumn{2}{c}{ NRP } \\
\cline { 2 - 3 } \cline { 5 - 6 } \multicolumn{1}{c}{ Day 0} & Day 28 & & Day 0 & Day 28 \\
\hline WBC $\left(* 10^{3}\right.$ cells $\left./ \mu 1\right)$ & $10.04 \pm 0.79$ & $12.19 \pm 1.37$ & & $18.17 \pm 4.47^{*}$ & $17.09 \pm 2.02$ \\
BUN $(\mathrm{mg} / \mathrm{dl})$ & $67.35 \pm 19.55$ & $39.83 \pm 8.97$ & & $74.43 \pm 15.42$ & $54.85 \pm 12.46$ \\
Cr $(\mathrm{mg} / \mathrm{dl})$ & $2.35 \pm 0.50$ & $2.38 \pm 0.29$ & & $2.72 \pm 0.36$ & $2.37 \pm 0.39$ \\
Iron $(\mu \mathrm{g} / \mathrm{dl})$ & $143.0 \pm 19.7$ & $88.3 \pm 16.8^{\dagger}$ & & $76.8 \pm 16.2^{*}$ & $73.3 \pm 10.9$ \\
TIBC $(\mu \mathrm{g} / \mathrm{dl})$ & $318.0 \pm 35.9$ & $282.5 \pm 19.9$ & & $215.8 \pm 21.0^{*}$ & $259.3 \pm 21.6$ \\
\%Sat & $46.07 \pm 6.29$ & $30.68 \pm 4.78$ & & $36.41 \pm 6.74$ & $28.02 \pm 3.61$ \\
Hepcidin $(\mathrm{ng} / \mathrm{ml})$ & $4.63 \pm 3.01$ & $4.27 \pm 2.56$ & & $6.08 \pm 2.20$ & $6.29 \pm 2.87$ \\
\hline
\end{tabular}

Data are presented as mean \pm standard error of mean. $\dagger P<0.05$ compared to day 0 in the same subgroup using paired $t$-test. $* P<0.05$ compared to day 0 of responder subgroup using unpaired $t$-test. RP: Responder; NRP: Non responder; WBC: white blood cells; BUN: blood urea nitrogen; Cr: Creatinine; TIBC: total iron binding capacity; \%Sat: The percent saturation of TIBC binding to iron.

in circulation is associated with iron overload or inflammation. Transferrin is indirectly measured and reported as TIBC. The ratio of serum iron concentration to TIBC is the \%Sat which is the percentage of TIBC that is occupied by iron and could be as low as $20 \%$ in case of iron deficiency (normal 20-50\%) [1].

In our study, albumin and TIBC were significantly lower in CKD-3 and CKD-4 groups compared with CONT group. Previous study showed that CKD cats also had lower both serum iron concentrations and TIBC compared with healthy cats [18]. The reduction in plasma albumin may be due to either low albumin production or its loss. None of dog in CKD groups had hepatic failure. Moreover, the low protein intake was not a case since dogs consuming renal diet had normal protein and albumin concentrations [4, 6]. Therefore, the albumin loss may be the main cause of hypoalbuminemia. Leakage of albumin may involve gastrointestinal or renal loss. We proposed that the urinary albumin loss was rather be a cause sinsce most of CKD dogs did not showed sign of diarrhea. In albuminuria, not only albumin was leaked into the urine, other proteins with similar or lower molecular weight may also be lost. The correlation between urinary excretion of transferrin and albumin was found in diabetic nephropathy [21]. Increased transferrinuria in the microalbuminuric stage leading to the development of tubulointerstitial injuries in type 2 diabetic patients was also suggested [20]. Since the urine/serum ratio of transferrin and albumin in diabetic patients were identical, therefore, the glomerular leakage and tubular 
handling for these proteins may be similar [15]. Study in stage I CKD cats showed that higher urine albumin and transferrin were found in CKD compared with normal cats [23]. The sensitivity of urinary albumin was higher, whereas the specificity was low than that of urinary transferrin. However, leakage of transferrin precedes that of albumin and urinary transferrin can be used for early diagnosis diagnostic marker for renal disorder in cats. We found the positive relationship between plasma albumin and TIBC in the present study suggested the possible loss of both substances in the urine. Unfortunately, the quantification of urinary proteins using protein creatinine ratio were not performed, although the urinalysis results showed that 20 out of 22 CKD dogs had proteinuria.

In addition to its loss in the urine, transferrin concentration can also change depending on nutritional state. Nutritional supplement in malnourished dogs caused higher plasma transferrin compared with before treatment which can be used to assess nutritional condition in dogs [27]. Plasma transferrin concentration was decreased in anorexic dogs with various diseases and in experimentally induced undernourished dogs [28]. Thus, decreased transferrin in

CKD can be partly due to malnutrition in CKD dogs since some dogs in CKD-3 and CKD-4 groups had anorexia.

In the present study, hepcidin concentrations in control healthy dogs were not different from dogs with CKD. However, when considering only CKD dogs, hepcidin concentration was lower in anemic dogs than those without anemia. These data suggested that hepcidin may not be responsible for anemia in these CKD dogs. Hepcidin is a small acute phase protein produced by liver and defined as a hormone with multiple functions. Hepcidin also involves iron metabolism and subsequently erythropoiesis by inhibiting intestinal iron absorption and blocking iron transport across placenta and iron release from macrophage as reviewed earlier [11]. Hepcidin is usually associated with C-reactive protein which found during inflammatory process. Higher hepcidin was found in cats with CKD and was associated with decreased TIBC and PCV [18]. It was suggested that systemic inflammation appears to be a key role for CKD cats. Moreover, hepcidin overexpression was found in hepatic adenoma patients resulting in severe iron-refractory anemia [37]. The reason for lower hepcidin in anemic CKD dogs in the present was unclear but may not be involved the inflammatory process but may be due to hypoxia. Previous study in human and mice showed that hypoxia caused down regulation of hepcidin via elevated platelet delivered growth factor BB [34]. In mice, the iron concentration was also increased. It is possible that anemia in CKD dogs may sequentially downregulate hepcidin while iron concentration could bot be increased due to its loss.

Some CKD dogs received iron supplementation during course of treatment. Nevertheless, iron supplementation showed no effect on iron parameters. The low gastrointestinal absorption of iron may occur in CKD if patient receiving phosphate binder. In dialysis CKD patients, intravenous iron administration is preferred and more effective than oral route [9, 14].

\section{Experiment II}

Both iron and TIBC are important factor for erythropoiesis and were lower in NRP than RP subgroup prior to darbepoitin alfa injection. The levels of iron of dogs in NRP subgroup was extremely low compared with other CKD dogs. The severity of proteinuria between RP and NRP groups may play a role on iron status and erythropoietic response to darbepoietin. Two dogs in RP group did not have proteinuria while other two had proteinuria of +1 and +2 . However, in NRP group, the proteinuria of +2 and +3 were found in four and one dogs, respectively. Previous report also showed that iron deficiency by urinary leakage was demonstrated in six out of nine human patients with nephrotic syndrome [2]. Therefore, higher urinary iron loss was proposed in NRP subgroup. After darbepoietin alfa administration, iron concentration only in RP subgroup was reduced significantly. These results indicate the important role of iron in red cell production as seen in hemodialysis patients in which the low-dose intravenous iron therapy can maintain iron store and hemoglobin level and reduced the dose of EPO [33]. While circulating iron is important for erythropoietic response to darbepoietin alfa, the TIBC level had significant positive relationship to the percentage changes in PCV. Therefore, TIBC may be used as a marker for the degree of erythropoiesis response to darbepoetin alfa administration.

Another possibility of low erythropoiesis may be due to EPO leakage in the urine. The urinary loss of both EPO and transferrin and their metabolism in nephrotic syndrome was reviewed [35] and reduction of both could be responsible for anemia in CKD and prevent normal erythropoiesis after EPO injection. Whether darbepoetin alfa with higher molecular weight than EPO had urinary leakage needs further investigation.

No significant difference of changes of hepcidin among RP and NRP subgroups both before and after 28 days of darbepoetin alfa treatment was found in this study. Variable results of hepcidin levels were found previously. Anemia caused by long term inflammation using turpentine oil administration in dogs resulting in acute increase in hepcidin mRNA expression that reduced to lower level later on [3]. Study in congenital portosystemic shunt dogs after surgical correction showed increase red blood cell without alteration of hepatic gene expression of hepcidin [8]. Lastly, a study in healthy dogs showed no correlation between 
hepcidin level and RBC number, hemoglobin, iron, iron binding capacity and C-reactive protein [36]. Thus, erythropoiesis is controlled and modulated with various factors, and the hepcidin level alone should not be used as a biomarker for erythropoietic status.

In conclusion, TIBC plays an important role on both anemia and erythropoiesis response to darbepoetin alfa. Moreover, it could be used as a marker for predicting the responsiveness to darbepoetin alfa treatment in dogs. Whether low TIBC involves degree of proteinuria needs further investigation.

\section{Limitation of the study}

The dogs with chronic kidney disease were presented as outgoing patients with stable disease at the hospital. Some dogs may receive fluid therapy after blood collection. The concurrent diseases if present, were treated with necessary medication such as antibiotics for blood parasite or urinary tract infection. Moreover, the urinalysis could not be obtained in all dogs during blood collection.

POTENTIAL CONFLICT OF INTEREST. We certify that there is no conflict of interest with any financial organization regarding the material discussed in the manuscript.

ACKNOWLEDGMENTS. This study was supported by Research Funding, Faculty of Veterinary Science, Chulalongkorn University. The authors would like to thank Nephrology clinic staffs, The Small Animal Teaching Hospital, Chulalongkorn University for providing data and facilities. We also thank Best Agro Co., Ltd. for the SDMA Vcheck ${ }^{\circledR}$ machine analysis. We appreciate Ms. Siripen

Komonvanich for her assistance in hepcidin analysis.

\section{REFERENCES}

1. Bohn, A. A. 2013. Diagnosis of disorders of iron metabolism in dogs and cats. Vet. Clin. North Am. Small Anim. Pract. 43: 1319-1330, vii. [Medline] [CrossRef]

2. Brown, E. A., Sampson, B., Muller, B. R. and Curtis, J. R. 1984. Urinary iron loss in the nephrotic syndrome-an unusual cause of iron deficiency with a note on urinary copper losses. Postgrad. Med. J. 60: 125-128. [Medline] [CrossRef]

3. Chikazawa, S., Nakazawa, T., Hori, Y., Hoshi, F., Kanai, K., Ito, N., Orino, K., Watanabe, K. and Higuchi, S. 2013. Change in serum ferritin concentration in experimentally induced anemia of chronic inflammation in dogs. J. Vet. Med. Sci. 75: 1419-1426. [Medline] [CrossRef]

4. Cortadellas, O., Talavera, J. and Fernández del Palacio, M. J. 2014. Evaluation of the effects of a therapeutic renal diet to control proteinuria in proteinuric non-azotemic dogs treated with benazepril. J. Vet. Intern. Med. 28: 30-37. [Medline] [CrossRef]

5. Dahlem, D. P., Neiger, R., Schweighauser, A., Francey, T., Yerramilli, M., Obare, E. and Steinbach, S. M. L. 2017. Plasma symmetric dimethylarginine concentration in dogs with acute kidney injury and chronic kidney disease. J. Vet. Intern. Med. 31: 799-804. [Medline] [CrossRef]

6. Finco, D. R., Crowell, W. A. and Barsanti, J. A. 1985. Effects of three diets on dogs with induced chronic renal failure. Am. J. Vet. Res. 46: 646-653. [Medline]

7. Fiocchi, E. H., Cowgill, L. D., Brown, D. C., Markovich, J. E., Tucker, S., Labato, M. A. and Callan, M. B. 2017. The use of darbepoetin to stimulate erythropoiesis in the treatment of anemia of chronic kidney disease in dogs. J. Vet. Intern. Med. 31: 476-485. [Medline] [CrossRef]

8. Frowde, P. E., Gow, A. G., Burton, C. A., Powell, R., Lipscomb, V. J., House, A. K., Mellanby, R. J. and Tivers, M. S. 2014. Hepatic hepcidin gene expression in dogs with a congenital portosystemic shunt. J. Vet. Intern. Med. 28: 1203-1205. [Medline] [CrossRef]

9. Gafter-Gvili, A., Schechter, A. and Rozen-Zvi, B. 2019. Iron deficiency anemia in chronic kidney disease. Acta Haematol. 142: 44-50. [Medline] [CrossRef]

10. Gammella, E., Diaz, V., Recalcati, S., Buratti, P., Samaja, M., Dey, S., Noguchi, C. T., Gassmann, M. and Cairo, G. 2015. Erythropoietin's inhibiting impact on hepcidin expression occurs indirectly. Am. J. Physiol. Regul. Integr. Comp. Physiol. 308: R330-R335. [Medline] [CrossRef]

11. Ganz, T. and Nemeth, E. 2016. Iron balance and the role of hepcidin in chronic kidney disease. Semin. Nephrol. 36: 87-93. [Medline] [CrossRef]

12. Hall, J. A., Yerramilli, M., Obare, E., Yerramilli, M., Almes, K. and Jewell, D. E. 2016. Serum concentrations of symmetric dimethylarginine and creatinine in dogs with naturally occurring chronic kidney disease. J. Vet. Intern. Med. 30: 794-802. [Medline] [CrossRef]

13. Hall, J. A., Yerramilli, M., Obare, E., Yerramilli, M., Melendez, L. D. and Jewell, D. E. 2015. Relationship between lean body mass and serum renal biomarkers in healthy dogs. J. Vet. Intern. Med. 29: 808-814. [Medline] [CrossRef]

14. Hörl, W. H. 2007. Clinical aspects of iron use in the anemia of kidney disease. J. Am. Soc. Nephrol. 18: 382-393. [Medline] [CrossRef]

15. Howard, R. L., Buddington, B. and Alfrey, A. C. 1991. Urinary albumin, transferrin and iron excretion in diabetic patients. Kidney Int. 40: $923-926$. [Medline] [CrossRef]

16. IRIS, International Renal Interest Society. 2016. IRIS Staging of CKD. http://www.iris-kidney.com/pdf/3_staging-of-ckd.pdf [accessed on January 4, 2020].

17. IRIS, International Renal Interest Society. 2019. IRIS Staging of CKD. http://www.iris-kidney.com/pdf/IRIS_Staging_of_CKD_modified_2019.pdf [accessed on July 20, 2020].

18. Javard, R., Grimes, C., Bau-Gaudreault, L. and Dunn, M. 2017. Acute-phase proteins and iron status in cats with chronic kidney disease. J. Vet. Intern. Med. 31: 457-464. [Medline] [CrossRef]

19. Jelkmann, W. 2011. Regulation of erythropoietin production. J. Physiol. 589: 1251-1258. [Medline] [CrossRef]

20. Kanauchi, M., Akai, Y. and Hashimoto, T. 2002. Transferrinuria in type 2 diabetic patients with early nephropathy and tubulointerstitial injury. Eur. J. Intern. Med. 13: 190-193. [Medline] [CrossRef]

21. Kanauchi, M., Nishioka, H., Hashimoto, T. and Dohi, K. 1995. Diagnostic significance of urinary transferrin in diabetic nephropathy. Nippon Jinzo Gakkai Shi 37: 649-654. [Medline]

22. King, L. G., Giger, U., Diserens, D. and Nagode, L. A. 1992. Anemia of chronic renal failure in dogs. J. Vet. Intern. Med. 6: 264-270. [Medline] [CrossRef] 
23. Maeda, H., Sogawa, K., Sakaguchi, K., Abe, S., Sagizaka, W., Mochizuki, S., Horie, W., Watanabe, T., Shibata, Y., Satoh, M., Sanda, A., Nomura, F. and Suzuki, J. 2015. Urinary albumin and transferrin as early diagnostic markers of chronic kidney disease. J. Vet. Med. Sci. 77: 937-943. [Medline] [CrossRef]

24. Marino, C. L., Lascelles, B. D., Vaden, S. L., Gruen, M. E. and Marks, S. L. 2014. Prevalence and classification of chronic kidney disease in cats randomly selected from four age groups and in cats recruited for degenerative joint disease studies. J. Feline Med. Surg. 16: 465-472. [Medline] [CrossRef]

25. McKenna, M., Pelligand, L., Elliott, J., Cotter, D. and Jepson, R. 2020. Relationship between serum iohexol clearance, serum SDMA concentration, and serum creatinine concentration in non-azotemic dogs. J. Vet. Intern. Med. 34: 186-194. [Medline] [CrossRef]

26. Nabity, M. B., Lees, G. E., Boggess, M. M., Yerramilli, M., Obare, E., Yerramilli, M., Rakitin, A., Aguiar, J. and Relford, R. 2015. Symmetricdimethylarginine assay validation, stability, and evaluation as a marker for the early detection of chronic kidney disease in dogs. $J$. Vet. Intern. Med. 29: 1036-1044. [Medline] [CrossRef]

27. Nakajima, M., Ohno, K., Goto-Koshino, Y., Fujino, Y. and Tsujimoto, H. 2014. Plasma transferrin concentration as a nutritional marker in malnourished dogs with nutritional treatment. J. Vet. Med. Sci. 76: 539-543. [Medline] [CrossRef]

28. Nakajima, M., Ohno, K., Takeuchi, Y., Takeuchi, A., Nakashima, K., Fujino, Y. and Tsujimoto, H. 2012. Usefulness of plasma transferrin levels as dynamic assessment of protein nutrition in dog. J. Pet Anim. Nutr. 15: 65-71.

29. Northrop-Clewes, C. A. 2008. Interpreting indicators of iron status during an acute phase response-lessons from malaria and human immunodeficiency virus. Ann. Clin. Biochem. 45: 18-32. [Medline] [CrossRef]

30. O’Neill, D. G., Elliott, J., Church, D. B., McGreevy, P. D., Thomson, P. C. and Brodbelt, D. C. 2013. Chronic kidney disease in dogs in UK veterinary practices: prevalence, risk factors, and survival. J. Vet. Intern. Med. 27: 814-821. [Medline] [CrossRef]

31. Reynolds, B. S. and Lefebvre, H. P. 2013. Feline CKD: Pathophysiology and risk factors-what do we know? J. Feline Med. Surg. 15 Suppl 1: 3-14. [Medline] [CrossRef]

32. Savarese, A., Probo, M., Locatelli, C., Zanzani, S. A., Gazzonis, A. L., Papa, M. and Brambilla, P. G. 2018. Reliability of symmetric dimethylarginine in dogs with myxomatous mitral valve disease as kidney biomarker. Open Vet. J. 8: 318-324. [Medline] [CrossRef]

33. Schiesser, D., Binet, I., Tsinalis, D., Dickenmann, M., Keusch, G., Schmidli, M., Ambühl, P. M., Lüthi, L. and Wüthrich, R. P. 2006. Weekly low-dose treatment with intravenous iron sucrose maintains iron status and decreases epoetin requirement in iron-replete haemodialysis patients. Nephrol. Dial. Transplant. 21: 2841-2845. [Medline] [CrossRef]

34. Sonnweber, T., Nachbaur, D., Schroll, A., Nairz, M., Seifert, M., Demetz, E., Haschka, D., Mitterstiller, A. M., Kleinsasser, A., Burtscher, M., Trübsbach, S., Murphy, A. T., Wroblewski, V., Witcher, D. R., Mleczko-Sanecka, K., Vecchi, C., Muckenthaler, M. U., Pietrangelo, A., Theurl, I. and Weiss, G. 2014. Hypoxia induced downregulation of hepcidin is mediated by platelet derived growth factor BB. Gut 63: 1951-1959. [Medline] [CrossRef]

35. Vaziri, N. D. 2001. Erythropoietin and transferrin metabolism in nephrotic syndrome. Am. J. Kidney Dis. 38: 1-8. [Medline] [CrossRef]

36. Vizi, Z., Lányi, K., Bagi, M., Laczay, P., Balogh, N. and Sterczer, Á. 2020. Serum hepcidin measurements in healthy dogs using liquid chromatography/tandem mass spectrometry. Vet. Clin. Pathol. 49: 292-298. [Medline] [CrossRef]

37. Weinstein, D. A., Roy, C. N., Fleming, M. D., Loda, M. F., Wolfsdorf, J. I. and Andrews, N. C. 2002. Inappropriate expression of hepcidin is associated with iron refractory anemia: implications for the anemia of chronic disease. Blood 100: 3776-3781. [Medline] [CrossRef]

38. Zaritsky, J., Young, B., Wang, H. J., Westerman, M., Olbina, G., Nemeth, E., Ganz, T., Rivera, S., Nissenson, A. R. and Salusky, I. B. 2009. Hepcidin--a potential novel biomarker for iron status in chronic kidney disease. Clin. J. Am. Soc. Nephrol. 4: 1051-1056. [Medline] [CrossRef]

39. Zucker, S., Friedman, S. and Lysik, R. M. 1974. Bone marrow erythropoiesis in the anemia of infection, inflammation, and malignancy. J. Clin. Invest. 53: 1132-1138. [Medline] [CrossRef] 